\title{
A VISION AND A MISSION FOR THE COLLEGE - A CHALLENGE AHEAD
}

\author{
Dr. L.B.L. de Alwis \\ Founder President, College of Forensic Pathologists of Sri Lanka. \\ Retired Chief Consultant Judicial Medical Officer, Colombo.
}

In November in the year 2010, The College of Forensic Pathologists of Sri Lanka celebrated 10 years of its existence. We as members of our College and our families along with rest of the Sri Lankan population of nearly 20 million entered the second millennium with great hopes and aspirations for the well being of all of us. Today we have entered the second decade of the new millennium with all hopes lost, in utter despair with a picture of 'gloom' not only for us and our children but for the entire "innocent law abiding ordinary citizens of our country.

This is because, today and over the past few years, we have been living in an era where politics have entered the mainstream of public life in our country as never before. This has resulted in a serious erosion of human values and social values affecting the day to day lives of the general public. Disappearances, abductions, extortions continue even after the end of the 30 years old terrorist war. Murders, sexual offences, assaults and other grave crimes not only continue but unfortunately some of them are not reported to the police authorities for fear of reprisals by victims as perpetrators of such crimes are thugs who work hand in glove with their political masters. Worst of all, disappearances, murders, assaults and threats made on journalists for highlighting such crimes against the society continues with the near total destruction of media institutions in a regular manner by arson and bombing by armed gangs who have never ever been identified up to now. This speaks volumes of the political partisanship let alone the gross 'inefficiency' of our law enforcement authorities.
Today only $4 \%$ of those accused of grave crime are found guilty while $96 \%$ of criminals are found 'not guilty and return to the society, to continue with their horrendous crimes threatening and intimidating those who complained against them to the police on earlier occasions or gave evidence against them resulting in a vicious cycle breeding more and more criminals with less and less members of the public coming forward to complain against them to the police let alone give evidence against them.

According to the Police Department statistics released a few years ago, there are nearly 40,000 Island Reconvicted Criminals (IRC) in the country. This is the direct outcome of politics (politicians and / or their agents) entering into and taking control of almost all the establishments designed, empowered and responsible for the administration of justice, upholding the rule of the law and maintenance of law and order in the society.

We also hear and read that suspects arrested by police officers for grave crimes such as murder, rape etc. have been shot dead in "self defense" by the same police officers who arrested them during the course of their investigations. The story almost always related by such police officers and their 'spokesman' is that such arrested suspects "handcuffed" and "fully guarded" by several armed police officers 'grabbed' a gun from a police officer and either shot or attempted to or shoot or throw a hand grenade hidden under some place or another and at times attempted to throttle the driver of the police jeep. In almost all such incidents the background story as related by the police spokesman is the same. Only the names of the 
killed suspects, the names of the police officers involved, name of the police station, place of the incident, date and times of such incidents varies.

Can we as Forensic Pathologists believe such "fairly tales"? Postmortem examinations on all such suspects shot and killed by the police in the name of so called "self defence" would have been performed by Forensic Pathologists who are Board certified specialists. As such have we as Forensic Pathologists in this country failed to use our expertise in the field to put a stop to these extra-judicial killings by advising the Judiciary that examination of the scene, "eyewitness accounts" and post examination findings does not fall in line with the story given by the police about the fatal shooting of the suspect in the name of self defence.

As Forensic Pathologists we know that any genuine crime detective will value the arrest of such suspects (and not kill them) as through them the detectives can identify other worst criminals, their "God fathers", the mafia behind such crimes and even their political masters, if there were any.

Such situations have resulted in the general public losing trust in the departments responsible for the administration of justice. Beginning from the Police Department, the general public has also lost faith in the legal system and the medical officers responsible for carrying out medico-legal services in the country which includes all of us as Forensic Pathologists.

This is the main reason for the present state of impunity in the country. Impunity means absolute disrespect for laws of the land which also includes disrespect for human and social values. This is because criminals know very well that they will never ever be arrested by the police and brought before a court of law. This impunity is the basis for crimes committed by certain politicians and thugs backed by such politicians who exercises control over police stations in their areas.

All along we as Forensic Pathologists simply sat back and blamed some person or another or an institution for such acts of injustice happening in our society. At times we were simply "silent" as we were not "bothered" as no injustice happened to "us". Even institutions responsible for the administrations of justice in turn blamed each other without putting their houses "inorder".

As Forensic Pathologists, we must be ready to accept our shortcomings if any, which may have led to this sad state of impunity. In which case, we must take immediate steps to put our house in order. Our College must prepare an action plan in consultation with all other institutions responsible for law enforcement, administration of justice and maintenance of law and order to arrest this state of deterioration of our society in the best interest of justice of our country.

During the past three decades, I functioned as a consultant at the Office of the JMO Colombo for 22 years and for 15 years as the Chief Consultant JMO (until my retirement in 2007) , I have observed vast developments in the field of Forensic Medicine, such as equipping mortuaries with 'coolers', x-ray facilities, photographic facilities, facilities for histopathological studies, medico-legal laboratory facilities etc. Today we have nearly 50 Board certified Forensic Pathologists both in the Health Department and the University Departments of Forensic Medicine to provide a medico-legal service to the country. In 1992 when I assumed duties as the Chief Consultant JMO there were only 6 Board certified Forensic Pathologists. 
Despite all these achievements, I have over the years clearly observed a downward trend in the attitude of the general public, the judiciary, and the legal profession towards medical officers carrying out medico-legal work in the country which includes all Forensic Pathologists. Petitions addressed to the judiciary and health authorities against Forensic Pathologists and other medical officers carrying out medico-legal work regarding their reports submitted to Courts of Law were often directed to me as the chief JMO Colombo for perusal and comments. By studying these reports along with comments made by the Judiciary, state prosecutors, criminal lawyers, other fellow medical practitioners and at times, comments about such reports in the press, I feel that all is "not too well" as regards the medico-legal services in our country and our role as forensic pathologists. The reasons for these are many.

Presently as much as $75 \%$ of medico-legal work in the country is carried out by medical officers who have had no special training in Forensic Medicine. Very many of them are "post-interns" carrying the label M.O. (Medico-Legal). As such the College must impress upon the health authorities that all medical officers carrying out medico-legal work in whatever capacity should have had a training of 2-3 months in a medicolegal unit under a Forensic Pathologist. All members of the College must co-operate with such training programmes. Even after such training, Forensic Pathologists must guide, advice and provide all assistance to these junior medical officers in carrying out their clinical medico-legal and postmortem examinations, submitting reports to courts of law and also when appearing in court to give evidence.

The College must impress upon the Ministry and the Department of Health, the Judiciary, Attorney General's Department, Bar Association of Sri Lanka, Sri Lanka Medical Association (SLMA), Organization of Professional Associates (OPA) and also the Sri Lanka Medical Council (SLMC), the urgent need to establish a vibrant Forensic Science Service which must as a priority include a forensic DNA laboratory. This is because DNA evidence is very vital and conclusive and also can replace evidence from lay witnesses who may be reluctant to give evidence, fail in their memory while giving evidence or even deliberately lie. It is been said that about $85 \%$ of those accused of murder are discharged due to lack of evidence as many lay witnesses do not appear to give evidence due to fear of reprisals, "bought over" or even "disposed of" before the trial.

It is said over and over again that "Justice delayed is Justice denied". We as Forensic Pathologists must ask ourselves the question as to whether "we as Forensic Pathologists" have contributed to this "Justice delayed and Justice denied". If so, as a College we must identify our shortcomings and rectify them. Some of these shortcomings I believe are delays in returning the police copy of the M.L.E. Form, delay in sending MLR, PMR and other reports to courts of law and non-attendance to give evidence in court trials. These short comings can be easily rectified by us if we recognize and respect our vocation as medical officers responsible for the administration of justice.

As Forensic Pathologists we must never condone torture of suspects, accused or prisoners. (Tokyo declaration of 1975). All cases of assault/torture while in custody of law enforcement authorities must be accurately documented and reported to the relevant authorities. Similarly if deaths occur while in 'custody' due to torture such fact must be reported without delay to the Magistrate holding the inquest into such a death. If on the other hand we as Forensic Pathologists are scared to report correct facts as regards such assaults, torture and deaths for fear of reprisals from the Police or other law enforcement authorities, than we must be ashamed about ourselves and leave our jobs as Forensic Pathologists forthwith and allow another fearless person to take our place in the best interest of justice. 
A Forensic Pathologist is entitled to give evidence in a court of law as a "defence medical expert" even though he/she has not carried out the relevant medico-legal or postmortem examination. The defence calls upon such Forensic Pathologists to express opinions as regards to reports already submitted or evidence given by another medical officer who may be a Forensic Pathologist or even a junior medical officer. In such instances the "Forensic Pathologist" appearing for the defence must express only "alternate" opinions based on his knowledge and experience to assist the Court to arrive at the "truth". He should never criticize, run-down or "pick holes" in the report/evidence of another medical officer before Court. I am of the firm belief that a Forensic Pathologist must give evidence for the defence only in the interest of preventing a "miscarriage" of justice. The fee offered to him by the defence or the outcome of the trial should never be his concern. In fact I would advice all Forensic Pathologists who "appear for the defence" to appear "free of charge" if the main purpose of appearing for the defence or advising the defence is to prevent a 'miscarriage of justice".

Further it must be remembered that under the Adversarial System of justice as practiced in Sri Lanka, the chances of an innocent person getting convicted is less than even $0.1 \%$ while the chances of a criminal getting acquitted is over $90 \%$. We must remember that just as less than $0.1 \%$ of innocent persons getting convicted, is a miscarriage of justice, the acquittal of over $90 \%$ of criminals who have committed the most dastardly crimes is a much much greater miscarriage of justice crying into the heavens. As Forensic Pathologists we must bear this in mind when giving evidence as 'defence' medical experts. Ask your self the simple question if the offence committed by such accused was murder, rape or assault and the victim was one of your loved ones would you have given evidence as a 'defence medical expert even for several hundred thousands of rupees. The same principle arises when you give evidence for the defence for several hundred thousand rupees when the victims are other people's loved ones. Further what would have been your reaction to another Forensic Pathologist who has appeared for the defence for a 'good fee' when the victim was one of your loved ones.

This is serious food for thought for all Forensic Pathologists who appear as "defence medical experts" merely for the sake of financial considerations. Such "defence" forensic medical experts after giving evidence must always ask themselves the question "did my evidence for the defence contribute to the acquittal of the murderer or rapist. If so has my role and vocation as a Forensic Pathologist to bring "justice through medicine" to our society been an utter failure. If so, should I continue any more as a Forensic Pathologist as I have failed in my mission and vocation to bring justice and fair play to the society through medicine.

At times, Forensic Pathologists conducting postmortem examinations may come across obvious cases of medical negligence for which a forensic pathologist does not require any special knowledge on the subject. Such cases of obvious negligence must be brought to the notice of the Inquirer, Magistrate without delay without any malice to the medical officer/s for such neglect, but in the best interest of the medical profession in general and the society whom they are serving. Covering up of such cases of negligence by Forensic Pathologists amounts to "serious professional misconduct".

At times, the Judiciary questions the 'truthfulness' of certain medical certificates issued by even medical specialists expressing opinions that persons who are mostly VVIP are unable to attend court on trial dates. I have examined several such VVIP and found that many of such persons were fit to attend court, and that the medical certificates were 'false' 
and have reported to court accordingly. This was just one way in which I was able to uphold the dignity and the honour of the Office of the JMO Colombo, during my career as the Chief JMO Colombo. As such as Forensic Pathologists we must have the courage to express independent opinions even though such opinions we express are contrary to opinions expressed by other medical officers who may be our colleagues, seniors or even our teachers. This is one way, we as Forensic Pathologists can discipline the entire medical profession. Further it will be a yard stick for the Judiciary to measure our honesty and integrity as Forensic Pathologists.

As Forensic Pathologists we need to be honest, sincere and truthful right throughout are career and also after our retirement as we still can be called upon to submit reports and give evidence in courts or law. Our honesty, sincerity and truthfulness must be $100 \%$ and not even $99.9 \%$. Then only we can be proud about ourselves and our profession and command the respect of the judiciary, the legal profession, law enforcement authorities, colleagues in the medical profession and the general public.

To build a good medico-legal service in our county we need "good" Forensic Pathologists. Therefore the College must advice the Postgraduate Institute of Medicine, the necessity to 'screen' all medical officers entering the postgraduate courses in forensic medicine. So that all Forensic Pathologists in our country will be men and women of integrity. One "bad egg" among the Forensic Pathologists is sufficient to discredit and ruin the entire medico-legal service of the country.

It is my belief that a Forensic Pathologist must have only a 'few friends' who will respect him and also the dignity of the profession. Do not associate with people whom you feel can harm your reputation. They may be your close friends or even your relations. In such instances keep them at arms length. Never ever ask for any undue favours from them however powerful they may be such as politicians, senior police officers, social workers etc., for at a later date they may ask for favours from you in return. Granting of such favours may amount to doing something dishonest and against your conscience affecting not only your dignity but the dignity of the entire, 'profession' and the field of Forensic Medicine.

Your reputation once tarnished can never ever be resorted for the rest of your life left alone during your career. Each time you stand on the witness box to give evidence, the defence counsel or even the prosecuting counsel may dig up your past misdemeanour much to your annoyance and embarrassment for which you could do nothing. In a court of law it is the "credibility "of a Forensic Medical Expert that is more important than the position held such as professor, senior lecturer, consultant JMO etc. or even the, knowledge and experience of such experts. Time and again courts of law have not accepted the evidence of "some top medical experts" for lack of credibility. The Judiciary, the Attorney General's Department and even the Unofficial Criminal Bar have their own yard sticks to measure the "credibility" of Forensic Medical Experts. Thus, we must remember to speak "the whole truth and nothing but the truth" at all times whether we appear as a prosecution witness or as a defence witness.

For medical practitioners in other branches of medicine, mainly those in the curative fields (with unlimited financial gains in private practice), the practice of medicine is only a profession. But for us as Forensic Pathologists it is not only a profession but more so a vocation needing much personal sacrifice because a Forensic Pathologist form part of the system that is responsible for the proper administration of justice, law and order on which depends the functioning of a "civilized society". 
When we try to act correctly in the discharge of our duties as Forensic Pathologists in order to preserve and maintain the dignity of our profession, there may be angry winds, cyclones, tornados and tsunamis that may attempt to destroy us. But we must act individually and collectively as a College to rise up against all such threats and stand unshaken as a rock fortress weathering all such threats and storms. For this we must be "united as a College" with common goals and objectives. This is what the society expects from us as Forensic Pathologists. We as forensic pathologists must strictly adhere to the Hippocratic Oath and all other declarations of the World Medical Association (WMA) which includes.

1. Declaration of Geneva (1948) and further amended in Sydney in 1968 and Stockholm (1944).

2. International Code of Medical Ethics. (ICME)

3. Declaration of Sydney (1968) - referring to the definition of death.

4. Declaration of Oslo (1970) referring to therapeutic abortions.

5. Declaration of Munich (1973) - referring to racial and political discrimination in medical treatment.
6. Declaration or Tokyo (1975) - referring to doctors attitude to torture and other degrading treatment of prisoners.

7. Declaration of Helsinki (1978) referring to human experimentation and clinical trials.

8. Declaration of Lisbon (1980) - referring to patient's right.

9. Declaration of Venice (1983) - referring to ethics in respect of terminal illnesses

Adherence to the Hippocratic Oath, other declarations of the World Medical Association (WMA) and other guidelines outlined by me in this article will make forensic pathologists the Perfect Medical Practitioners. Let me conclude by stating what I have said most often to my trainees and students. "Forensic medicine is the only branch of medicine that can make a man a gentleman and a woman a lady".

This article was written by me in the best interest of the future of the College and the field of Forensic Medicine. 